\title{
A SEIVA DO PASSADO NO SABER HISTÓRICO PORTUGUÊS E CASTELHANO (XIV-XV)
}

\author{
Susani Silveira Lemos França* \\ susanilemos@uol.com.br
}

RESUMO: A proposta deste estudo é, a partir da análise das crônicas dos séculos XIV e XV, lançar luz sobre os topoi usados pelos cronistas/historiadores deste tempo para afirmar e reafirmar que seus escritos deviam ser lidos como fonte de ensinamentos. Lançando, pois, mão do topos da história como mestra da vida e remodelando-o de acordo com seus interesses presentes, os cronistas ordenaram o passado a partir desta ideia regulativa. Que papel cumpre este ideal na construção da sua história é justamente o objetivo do estudo, todavia, com ênfase no impasse que enfrentaram os cronistas que tiveram que valorizar o passado, mas justificar uma ruptura, ou seja, os historiadores que trataram das duas crises sucessórias originadoras de novas dinastias: Avis, em Portugal, e Trastâmara, em Castela.

PALAVRAS CHAVE: Escrita da história; Pero Lopez de Ayala; Fernão Lopes.

A utilidade de historiar foi cantada na Idade Média das mais diversas formas, mas amparou-se acima de tudo na máxima ciceroniana do alimento sucessivo dos tempos, em que o passado aparecia como o sêmen dos períodos posteriores. Historiadores medievais célebres, provenientes dos mais diversos reinos europeus, contribuíram com ao menos um tijolo para que aquilo que parecia certo fosse deixado sem sombra de dúvidas: o aperfeiçoamento dos homens no tempo dependia do passado. Ainda no século XIII, o monge inglês Roger de Wendover (falecido em 1236), da escola de Santo Albano, empenhado na afirmação desse potencial do passado como único alimento possível do vir a ser, chega a ser ríspido com "certos cavaleiros obtusos que questionam qual a necessidade de recordar a vida e a morte dos homens, ou as várias sortes que tiveram; ou de confiar à escrita os prodígios diferentes do céu, da terra e dos elementos". A esses responde categoricamente que gostaria que soubessem "que os exemplos dos homens bons dos tempos passados são descritos para a imitação nos tempos que se sucedem; e os exemplos de homens maus, quando ocorrerem, não devem ser seguidos, mas evitados (WENDOVER, 1849, p. 1).” Uma fórmula simples que, sem dúvida, de tão repetida, tem sido percebida como topos dos escritos históricos

\footnotetext{
* Doutora em História. Professora da Faculdade de Ciências Humanas e Sociais da UNESP/Franca
} 
medievais, como uma configuração estável, com função meramente retórica. Mesmo, porém, que se possa admitir seu baixo índice de variação, isso não deve ser confundido com ausência de significado histórico. Afinal, a própria retórica medieval, com seus elos com a ética, deve ser estudada na sua historicidade e pelos diálogos de múltiplos caminhos, sempre renovados, que manteve com a retórica grega e a latina (CARRUTHERS, 2002, p. 264).

A afirmação, pois, sobre o papel do passado como alimento dos tempos subsequentes, pelo seu caráter repetitivo, apesar de aparentemente irrefletida, funciona nesses escritos como uma espécie de ponto de partida da história, como uma sugestão para a linha de pensamento a seguir e os primeiros aspectos a destacar. Seu caráter ostensivo nas crônicas destinadas à afirmação dos reis e dos estados que foram sendo forjados no final da Idade Média não esconde a preocupação dos historiadores em afirmar por que razão estes se dispunham à tarefa de dar ordem às coisas passadas. $\mathrm{O}$ que, pois, importa questionar é que espaço e configurações ganha o lugar comum e que argumentos ou relações surgem a partir dele nas crônicas castelhanas e portuguesas dos séculos XIV e XV, período em que as crises sucessórias que resultaram na ascensão de novas dinastias, Avis e Trastâmara, ${ }^{1}$ levaram a que aquela fórmula do passado como inspirador dos demais tempos se sustentasse sobre um paradoxo: a recordação do passado deveria justificar uma ruptura. O empenho de, por intermédio da escrita, encontrar argumentos para legitimar os fundadores das duas dinastias e seus sucessores começa, pois, com a ênfase sobre a função da história de servir de receptáculo de experiências alheias, instrutivas, edificantes, para repetir os êxitos passados e evitar no presente os erros. Uma ênfase que persistiu depois da Idade Média, ${ }^{2}$ continuou a ter certa presença no senso comum dos tempos posteriores e não foi abalada nem mesmo com as quebras dinásticas.

O topos surge, em geral - inclusive em crônicas contemporâneas de outros reinos -, nos prólogos ou capítulos iniciais, portanto, sua validade pode ser atestada por essa primazia e pelo fato de que, posteriormente, esse sentido ético da história continua a ser cantado e reafirmado, sob a luz dos ensinamentos de S. Agostinho, especialmente no que diz respeito à moralização da memória e ao entendimento de que esta era uma parte da virtude da Prudência (YATES, 2007, p. 80-81; RICOUER, 2000, p. 76), como mais tarde será ordenado por São Tomás de Aquino (1980, p. 223). João de Barros (1496-1570), nas suas décadas da Ásia, define a história em termos que justamente 
reafirmam o seu ideal pedagógico (GUENÉE, 1980, p. 27-29), ao apresentá-la como um campo onde toda doutrina poderia ser cultivada. Apela, pois, para a metáfora da semeadura para anunciar os terrenos em que a semente da história poderia germinar, no “divinal, moral, racional e instrumental". Aquele, pois, que provasse do "seu fruto", estaria apto a convertê-lo "em forças de entendimento e memória, para uso de justa e perfeita vida, com que apraz a Deus e aos homens" (JOÃO DE BARROS, 1988, prólogo). Mais até que Agostinho, o Tito Lívio português recordava Cícero e sua proposição de que o olhar sobre o passado deveria ter em vista a prática virtuosa, dado que se inspirava em um jogo de causalidades em que, entre as quatro partes da Virtude, Prudência, Justiça, Fortaleza e Temperança, se destaca a primeira, a Prudência. Esta, por sua vez, servia justamente para delimitar o conhecimento do que é bom ou ruim a partir, sobretudo, daquela de suas partes, a Memória, que se destacava em relação às outras - a inteligência e a previdência -, porque era vista como a própria chave para a virtude humana. Em outras palavras, sendo a base da memória e da história a recordação ou

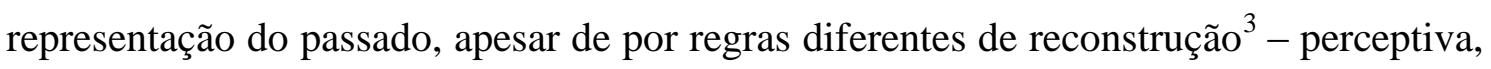
sensorial, afetiva, no caso da memória, e não elaborada e racionalizada com certo distanciamento, na forma oral ou escrita, como a história -, ambas, quando analisamos a história medieval, por trabalharem com matéria coincidente, partilhavam a prerrogativa de definir o bem e o mal e de ser "guia imortal para o comportamento virtuoso" (COLEMAN, 1992, p. 42-47).

Tal dimensão preceptiva da história é igualmente corroborada por outro cronista português reconhecido como dos descobrimentos, Fernão Lopes de Castanheda (1500-1559), que estabelece uma linha de continuidade para a história remontando aos reis do Egito, habituados a ter, a "cada dia lição das histórias, não somente de seus antecessores, mas de outros reis estrangeiros". E eles o faziam, pelo que sugere o cronista, com o claro intuito de extrair dessas histórias "doutrina de como haviam de governar seus reinos na paz e na guerra". Costume de tomar exemplo do passado que o cronista, em contrapartida, não se exime de propor explicitamente - assumindo ele próprio seu compromisso pedagógico - como exemplo a ser tomado pelos reis do seu tempo. Castanheda reafirma assim o lugar comum de que a função da reconstrução histórica era guardar e ensinar, mas acrescenta um dado igualmente corrente e que remonta ao referido Cícero, o de que o aperfeiçoamento proporcionado pela história era não só corretivo, mas contínuo e cumulativo, "porque os que governam bem, o fariam cada vez melhor, e os que mal, se emendariam (pois nas histórias se acham os melhores 
exemplos que podem ser para qualquer estado de vida)" (CASTANHEDA, 1979, p. 205).

Não deixa também de ajuntar elementos ao topos o cronista sevilhano, Bartolomeu de Las Casas, o qual, sem deixar de reconhecer que a história ensina, opta por alertar para o perigo de incorrer na "pestilência mais perniciosa": a de ensinar mentiras ou enganar com lisonjas. $\mathrm{O}$ cronista, não imune à necessidade de reafirmar o caráter instrutivo da história, recorda Isócrates para alertar dos perigos da instrução reversa, ou melhor, para o risco das "palavras brandas e suaves", em especial quando tendentes a louvar no rei o que "não deve", ameaçando, assim, o seu próprio estado. Isso porque, explica o cronista, aqueles "que escrevem coisas fingidas" ou "os que fingem histórias não verdadeiras" atingem não apenas os que recebem as adulações, pois estas "contaminam aos reis, não só a um, mas a muitos presentes e futuros através de sua escritura perpétua; e por consegüinte, a seus reinos prejudicam" (BARTOLOMÉ DE LAS CASAS, 1875, p. 5-6). Eram assim, segundo o célebre cronista, que as histórias podiam descumprir aquilo que também ele entendia como sua razão de ser: ensinar coisas louváveis e não louvar não merecedores. Seu prólogo não difere substantivamente dos seus congêneres na defesa de que a história deveria ser a seiva das práticas virtuosas, contudo, ele opta por advertir das eventuais consequências opostas desse potencial interventivo, ou seja, alertando que não apenas o efeito positivo era prerrogativa da história, mas que os ensinamentos duvidosos poderiam trazer prejuízos significativos ao governante e aos governados, presentes e futuros. Sugere também sua reflexão, em que retoma ideais repisados e acrescenta valores que revelam os novos compromissos da história no seu tempo, que conferia aos escritos um peso políticosocial que não era de pouca importância, dada a sua inegável incidência sobre o que viria a ser.

Os antecessores desses cronistas no âmbito da Península Ibérica não diferiram muito no que diz respeito à valorização desta idealizada - mas não menos verdadeira, ${ }^{4}$ vale destacar - razão de ser da história. No proêmio das Crónicas de los Reyes de Castilla, Pero Lopez de Ayala (1332-1407), reafirmando a tópica da fragilidade da memória para contornar o tempo, apresenta os "livros, chamados de crônicas e histórias", como instrumento dos reis para que as "cavalarias e outras quaisquer coisas que os príncipes antigos fizeram" fossem por seus sucessores tomadas como estímulo para “fazer bem e se guardar de fazer mal” (LOPEZ DE AYALA, 1779- 
80, p. XIX). No Memorial de Diversas Hazañas, o cronista castelhano Mosen Diego de Valera (c. 1412-1488) justifica seu trabalho de escrita, para além de trazer à luz "façanhas e virtuosas obras", para que, pelo exemplo desses realizadores, outros se esforçassem para realizar obras à altura (DIEGO DE VALERA, 1878, p. 3). Não menos explícito que ele na atualização do topos, é outro cronista peninsular, Hernando Del Pulgar (Toledo, 1436? - 1493), servidor de Enrique IV e cronista real de D. Isabel. Na sua Crónica de los Señores reyes católicos Don Fernando y Doña Isabel de Castilla y de Aragon, destaca ele que a recordação do passado através da história portava o benefício de nos mostrar "no decurso desta vida o que devemos saber para seguir" (HERNANDO DEL PULGAR, 1780, p.1). Se este encaminhamento era em um sentido geral, rumo a um fim maior, a salvação, ${ }^{5}$ ou se tinha em vista o aperfeiçoamento pontual da governação ou de outras ações e gestos cotidianos, não se pode deduzir ao certo. Apenas é possível afirmar que a função instrutiva da história, para esses cronistas, não podia deixar de ser reafirmada.

Naturalizando, pois, a ideia de que o tempo devia ser o lugar do crescimento espiritual (GUITTON, 1959, p. 238), outros cronistas peninsulares da época de formação dos estados e das nações - entre os séculos XIII e XV - conceberam a história como instrumento para tal maturação; o que explica as incontáveis referências ao seu comprometimento pedagógico. Um comprometimento que, a propósito, podia se dar inclusive por vias opostas. Na citada compilação de crônicas intitulada Crónica de los Reys de Castilla, ${ }^{6}$ por exemplo, além de ser ressaltado que os bons feitos deviam ser lembrados, não é descartado que a história deveria incluir o que devemos saber "para ter aversão" (HERNANDO DEL PULGAR, 1780, p. 229). Não se tratava, pois, do ensinamento vicioso, para o qual adverte Las Casas, mas das lições formuladas a partir dos deslizes alheios para que outros não incorressem em mesmos erros. Ensinamentos por vias avessas que são, do mesmo modo, defendidos pelo cronista português Fernão Lopes, ao propor que as "contrárias coisas" deviam compor as histórias (FERNÃO LOPES, 1977, p. 2). Este, contudo, acrescenta outro dado que amplia o sentido do lugar comum, pois ocultar os desmerecimentos dos conterrâneos, alerta ele, poderia impedir que a história cumprisse sua missão de ensinar aos que depois viessem, pelo quê não podiam ser ocultados nem os equívocos de D. Fernando, nem os abusos justiceiros de D. Pedro I.

Lembrar os enganos, desregramentos ou falhas, mas destacar, sobretudo, o louvável era, pois, o que importava. Lopes exalta as "bondades" de D. João I, bondades 
notáveis na sua governação exemplar, de forma que aqueles que depois dele viessem, deveriam tomá-lo como "mestre" e com ele aprender "a ordenança do real regimento" (FERNÃO LOPES, 1977, p. 3). Seus sucessores, a seu modo, não se sentiram desobrigados de continuar afirmando que o fio condutor da narrativa histórica e os seus elos deviam ser as virtudes e os feitos louváveis. Gomes Eanes de Zurara, por exemplo, numa carta de 1453 dirigida a D. Afonso V, tratando menos de governação e mais de história sobre feitos expansionistas da nobreza portuguesa, menciona que a principal motivação de sua história centrada nos feitos do Infante D. Henrique não era recompensá-lo pelos seus feitos, perpetuando sua memória, mas sim prestar serviço aos tempos vindouros, pois seria lamentável que "de tão santa e tão virtuosa vida não ficasse exemplo" para os próprios portugueses e "para todos outros do mundo que de sua escritura cobrassem conhecimento". 7

Seguiu nessa mesma linha de defesa da história outro cronista castelhano, o também jurista Lorenzo Galíndez de Carvajal (1472-1525). No proêmio do seu Memorial y registro breve de los lugares donde el Rey y Reina Católicos estuvieron cada año, desde el año de sesenta y ocho en adelante hasta que dios los llevo para si [...], o cronista se sente empelido a apresentar as razões para que o gosto por recordar o passado - que talvez ele considerasse de alguma forma ameaçado - se mantivesse para além dos tempos. Seu argumento incide sobre o caráter universal da prática, uma prática aprovada "por longo decurso de tempo", além de celebrada e confirmada "por todas as nações e gentes dotadas de razão". Universalidade e duração, pois, devidas ao potencial da história de contornar a fugacidade, já que "no escrever se guarda o que se deve"; mas devidas, sobretudo, à sua natureza edificante, porque "nos dá maneira para bem e virtuosamente viver". Pela história, adita ele, "somos instruídos no fim que devemos seguir". Retoma assim Carvajal, como seu conterrâneo, a ideia de um fim condutor da existência, mas é mais claro quanto ao sentido transcendente deste, ao referir "aquela bem-aventurança para que fomos criados", a saber: encontrar a plenitude através de um plano oculto maior. ${ }^{8}$ Mais que outros cronistas, Carvajal atribui à crônica "autoridade para ser imitada e seguida", pois seria ela o instrumento principal pelo qual se poderia alcançar e pôr em obra "os atos virtuosos passados, fugindo-se e afastando-se dos vícios presentes" (GALINDEZ DE CARVAJAL, 1878, p.585).

Através desses topoi, portanto, os cronistas sustentam, articulando argumentos diversos, que a história era um instrumento para que o devir histórico rumo 
ao Paraíso se cumprisse. O citado elogio à história feito por Carvajal, sendo já do século XVI, faz-nos pensar, tal como no caso dos citados cronistas dos descobrimentos, em uma comunidade de valores para além da Idade Média e até muito depois do século XVI. Todavia, importa aqui não propriamente apontar continuidades, mas sim observar que os enunciados repetitivos não devem ser vistos como mera encenação sem qualquer conteúdo histórico. Se, nos séculos XV e XVI, o louvor da ordenação do passado se fazia, como em Isócrates, Cícero e muitos outros antecessores antigos e medievais, pelo seu reflexo nos tempos seguintes, essa persistência não foi eterna. A superioridade do tempo passado na organização do tempo histórico não pode ser vista como uma constante, já que em épocas posteriores, como os séculos XVIII e XIX, aqueles que refletiram sobre a história tiveram em mente menos os modelos do passado e mais a ideia de progresso ou evolução (LE GOFF, 1984, p. 346-351; GUINSBURG, 1993, p. 15), ou a projeção de um futuro sobre parâmetros ideais, como Kant (LACROIX, 2001, p. 107-113) ou Hegel (DOMINGUES, 1991, p. 272) - para ficarmos por apenas grandes exemplos. Se, pois, a repetição pode denunciar algo irrefletido, ela pode, do mesmo modo, ser lida como marca definidora e legitimadora de um gênero cuja especificidade era ordenar e atribuir valor ao passado: a crônica ou história.

Ao analisarmos as crônicas dos séculos XIV e XV, lançando luz sobre esse ângulo do comprometimento dos historiadores de afirmarem e reafirmarem que seus escritos deviam ser lidos como um meio de ensinamento, o que deve ser questionado não é a veracidade do que afirmam, mas o porquê de, naquela altura, tal tipo de afirmação poder ser tomado como verdadeiro e relevante. Neste breve inventário dos tópicos de afirmação da história como mestra, a proposta não foi, pois, desconfiar da sinceridade dos cronistas em razão do caráter convencional de suas afirmações, mas propor que, se este ideal podia ser afirmado como meta, é porque era crido como conforme com a realidade que partilhavam como verdadeira. Ou seja, se tomavam como ideal que à história cabia ensinar, este ideal não era menos real que as articulações que puderam fazer no âmbito dos seus escritos, ${ }^{9}$ de forma que convém, a partir de agora, questionar - como foi prometido no início deste estudo - não uma suposta história real em oposição às suas idealizações, mas o que se encontrava entre os aspectos incontornáveis a serem ensinados pelos historiadores - cujos escritos têm sido enquadrados no chamado gênero "crônica real" - (GÓMEZ REDONDO, 2000, p. 95108; FUNES, 2002, s/p), que trataram das duas crises sucessórias originadoras de novas dinastias: Trastâmara, em Castela, e Avis, em Portugal. 
Entre esses que tiveram de praticar certo malabarismo para, a despeito da ruptura, manter o passado como exemplo e buscar outros parâmetros de continuidade, tais como os parâmetros morais, encontra-se Pero Lopez de Ayala. Seus escritos precedem os dos cronistas portugueses - a primeira versão escrita de 1379 a 1383 , conhecida como Abreviada, e reescrita em 1388, conhecida como Vulgata - e sua demarcação temporal balizada anualmente é mais impositiva na organização do passado que a dos seus congêneres vizinhos. Ayala, para narrar circunstâncias contrárias, como o agitado período correspondente ao reinado de Pedro I, o Cruel, e para narrar a quebra na ordem considerada natural da história, quando se confrontaram Pedro I e Enrique de Trastâmara e quando a morte do primeiro implicou em uma etapa de consolidação de uma nova dinastia, lança mão de um rol de temas que anuncia já a maior variedade das formas e abordagens que virá a caracterizar a historiografia medieval peninsular do século XV (BECEIRO PITA, 2007, p. 374). Nesse rol, entretanto, pode-se notar certa regularidade no que diz respeito aos gestos e práticas, considerados bons e virtuosos para os grandes homens, a quem cabia reger bem, ou seja, de forma prudente, a si e aos outros. O chanceler, que foi personagem envolvido em parte dos eventos que narra e que teve de lidar com o problema da ascensão de uma nova nobreza, juntamente com a nova família régia, explorou, como os cronistas do seu tempo, a dimensão moralizante pelo exemplo negativo e positivo dos grandes homens e, do mesmo modo, conferiu na sua narrativa grande peso à vontade e à ação particular do rei no desdobramento das circunstâncias sociais e políticas da sua época.

O rei desequilibrado, D. Pedro I, de Castela, contrariando os deveres atribuídos aos reis, regere, dominar a si próprio, e corrigere, corrigir os outros (SENELLART, 2006, p. 23 e 72), surge como um cultivador de desvirtudes, do mesmo modo que um cruel ceifador de vidas, cuja ceifa macabra se vai acumulando ao longo dos anos com as mortes daqueles que se lhe opõem de alguma forma, como Garçi Laso de la Vega, Pero Núñez de Guzmán - cuja "maneira de sua morte seria assaz feia e crua de contar"-, Alfonso Fernandez Coronel, João Gonçalvez de Deça e, entre muitos outros, seus irmãos D. Fadrique e D. Telo. A banalização das mortes mandadas realizar pelo rei é tanto mais significativa quando são acrescidas indicações na narrativa da indiferença do rei em relação a elas, como, por exemplo, depois da morte de seu irmão D. Fadrique, sentou-se "a comer onde o Mestre estava morto, em uma quadra que dizem 
dos azulejos, que é em Alcazar". E logo a seguir começou a cuidar de outra morte (LOPEZ DE AYALA, 1779-80, p. 242 e 312).

Tendo em vista o referido lugar comum do sentido que atribuíam à história no seu tempo, o de que ela deveria ensinar, a inclusão, na versão Vulgata, da carta de aconselhamento do mouro Benahatin ao rei D. Pedro, na parte relativa aos anos finais do reinado desse rei, cumpre uma clara função de orientação para os reis póstumos pelo exemplo de um rei que não se apresentava como espelho para os outros. O mouro, que se põe justamente na posição de sensato conselheiro, primeiramente opina sobre o que eram as virtudes de um rei, como se manter em concórdia com seu povo, honrar "os grandes", respeitar o patrimônio dos súditos, não beneficiar os não merecedores e, entre muitas outras obrigações, manter a justiça e demonstrar afeição através da expressão do rosto e dos gestos generosos. Tudo o que garantiria a "benquerença" dos súditos e a paz do reino. Mas como D. Pedro, que deveria, em princípio, ser fonte de exemplos, não se mostrava nem de longe como um fiel seguidor desses ensinamentos positivos, o complemento da carta, em que as advertências suplantam as recomendações, cumpre melhor o objetivo pedagógico visando os futuros reis. Benahatin enumera as causas das danações dos reis: "e a principal é ter em pouco as gentes; a segunda é ter grande cobiça (...); e a terceira é cumprir suas vontades; e a quarta é desprezar os homens da lei; e a quinta é usar de crueldade". D. Pedro experimentou um pouco de cada uma dessas desvirtudes e, por sua grande cobiça de riquezas, concedia a alguns e iludia a outros grandes senhores e cavaleiros do seu reino (LOPEZ DE AYALA, 1779-80, p. 154-164, 487).

Nesse tempo, pois, em que a centralidade régia se afirmava, toda a organização do passado na forma de narrativa histórica se dava em torno da figura dos governantes, cujas ações e gestos incidiam no jogo entre o governo de si, da casa e do reino (SENELLART, 2006, p. 31), e deviam ser, portanto, o foco do registro, o fio da rememoração e o principal instrumento para as inserções pedagógicas. Um fio, contudo, em que menos importavam as pessoas de Pedro ou Enrique, mas suas atuações como reis, ${ }^{10}$ dimensão em que se depositava maior expectativa de exemplaridade (FERRO, 1991, p. 23-26). E D. Pedro, porque confundia crueldade com justiça e governava para o bem de si e não do reino, não servia senão como exemplo negativo; daí que sua crônica seja recheada de passagens em que, além de mortes, merecem destaque castigos, detenções, perseguições e outras ações não justificadas para os reis virtuosos. Em contraponto a ele, cognominado o Cru, não sem razão, emergia a personagem do futuro 
rei, cujos gestos eram, ao contrário, marcados pela ponderação. Ao contrário de Pedro, que ao longo de sua trajetória vai somando mortes, Enrique segue conseguindo adeptos, apoiando e sendo apoiado pela Igreja, favorecendo os nobres, etc., em suma, cumprindo as expectativas que os espelhos de príncipes estabeleceram para os reis. E se o faz, como devia ser para qualquer homem exemplar, não sem dificuldades e obstáculos (NOGALES RINCÓN, 2006, p. 12-15).

A história de D. Enrique II, pois, é uma história em que a ruptura é lida pelo seu cronista como vontade de Deus para corrigir o rumo dos desaires. Daí as diversas notícias sobre o reconhecimento da sua autoridade e apoio por homens como os "grandes e bons" de Sevilha de Burgos e de muitas outras partes. Daí, do mesmo modo, indicações de que passava e deveria passar entre outros reis como "homem cortês e bem razoável” (LOPEZ DE AYALA, 1779-80, p. 421-427 e 451), como pode demonstrar na resposta que deu ao Príncipe de Gales, que pretendia apoiar seu irmão nos conflitos que se estabeleceram entre eles visando o trono de Castela e Leão. Seus argumentos infrutíferos- para tentar angariar o apoio deste príncipe apelavam para outra tópica corrente nos escritos cronísticos, a de que os sofrimentos, "grandes trabalhos, danos e perigos de mortes" que se abateram sobre as gentes dos reinos de Castela e Leão teriam sido amenizados porque "Deus, por sua mercê, teve piedade de todos os destes reinos, para que não fosse este mal cada dia mais”. D. Enrique II apresenta-se, assim, como um instrumento da "misericórdia" de Deus para proteger aqueles reinos e utiliza o argumento de que a tal vontade de Deus acrescia o apoio de todos dos reinos, "prelados, cavaleiros e fidalgos" (LOPEZ DE AYALA, 1779-80, p. 452-453), como convinha nesta hora em que havia quebra na sucessão dinástica e era preciso confrontar duas concepções de poder: a descendente, que advogava que todo poder vinha de Deus; e a ascendente, que marcava a intervenção do povo na atribuição de poder ao rei (ULLMANN, 1992, p. 15). Ainda que apelando a esses argumentos correntes, porém, D. Enrique não consegue demover aquele príncipe de apoiar seu irmão rival.

Mais a oeste, em Portugal, a ordenação do passado para nutrir o presente e o futuro também implicou na justificativa de um corte na ordem considerada natural, a sucessão hereditária e dinástica. E ali também dois irmãos se tornaram chave na construção do passado pelos seus méritos e deméritos, contudo, diferentemente da quebra devida aos favorecimentos de uns em detrimento de outros nobres, que esteve na origem da disputa de poder pelos irmãos Enrique e Pedro nas terras castelhanas, no caso 
de Portugal, a organização do passado envolveu a conjugação de temporalidades diferentes, mas em ambos os casos nota-se o destaque para o peso da esfera moral nos desdobramentos políticos. Lá, em Castela e Leão, um irmão tinha confrontado outro, seu contemporâneo, em defesa, segundo o cronista Ayala, do bem de todos, e o culminar e desenrolar da história tinha sido a morte do sucessor, em princípio legítimo, de D. Alfonso XI; nas terras lusitanas, ao contrário, a morte casual de D. Fernando apresenta-se não como o cume da história, mas como uma espécie de ponto de partida ou começo de uma história em que a aparente renovação esconde, paradoxalmente, um empenho de retomada do passado, mas de um passado mais remoto e articulado pelos fins éticos. Não é à toa, por exemplo, que D. João I é apresentado, à semelhança de D. Dinis, "Príncipe de bom saber" (RUI DE PINA, 1977, p. 222; 1952, p. 4), como rei “de grande entendimento", além de praticante daquelas virtudes que um rei deve ter: "saber, justiça e piedade" (FERNÃO LOPES, 1977, p. 2). E não só ele como também seus sucessores de Avis gozaram de prestígio semelhante, recebendo de outros cronistas régios, por exemplo, designativos de "mui esclarecido Príncipe" ou de "homem sisudo e de claro entendimento, amador de ciência, de que teve grande conhecimento", e não por frequentar escolas, "mas por continuar de estudar, e ler bons livros" (RUI DE PINA, 1977, p. 488 e 495).

Nos dois casos, pois, dado ainda o peso da dimensão ética sobre o poder (BUESCU, 1996, p. 45), a ruptura na linha sucessória fica amenizada pela continuidade moral, ou melhor, o compromisso da história de alimentar-se do passado fica garantido quando, de um lado, Enrique faz lembrar os reis virtuosos antecessores de Pedro, o Cruel; e D. João I de Portugal, por suas virtudes e capacidade de governar fazendo uso da virtude medianeira entre as morais e as intelectuais, a prudência (GARCÍA DE CASTROJERIZ, 2005, p. 75), ganha legitimidade pela imagem de salvador que o cronista Fernão Lopes, corroborado por Zurara, atribui a ele (VENTURA, 1997, p. 34). Se Enrique de Trastâmara tinha sido apresentado como mais liberal para com os nobres que seu irmão, além de interventor em favor de uma justiça mais equilibrada e do fim “das cruezas de sangue e mortes” (LOPEZ DE AYALA, 1779-80, p. 540), D. João de Avis é mais claramente exaltado por suas mais elevadas dignidades, que não só o avantajavam em relação aos seus concorrentes e ao seu antecessor, como pareciam inclusive singularizá-lo entre as principais referências do passado que alimentaram as histórias dos cronistas. Fazendo jus aos ensinamentos de Egídio Romano, cuja obra foi referência incontornável para os cronistas, e que pregava que, entre os quatro graus de 
"amor ordenado", vinha em primeiro lugar o "amar a Deus sobre todas as coisas do mundo" (GARCÍA DE CASTROJERIZ, 2005, p. 248-249) - ensinamento corroborado pelo infante D. Pedro, que, no topo das virtudes que elevariam o rei, propõe que "seja Católico, e muito firme na Fé” (RUI DE PINA, 1977, p. 496; Livro dos Conselhos de El-rei D. Duarte, 1980, p. 74-78) -, D. João I e seus descendentes, mais que seus antecessores, mereceram dos historiadores designações sobre sua devoção. Antes mesmo de ser coroado, o Mestre de Avis viu reconhecida essa sua virtude através do discurso do jurista João das Regras, que, em favor de sua eleição ao trono, advogou ser ele um candidato que preenchia os requisitos para a missão régia, a começar por "ser devoto e encaminhar seus feitos segundo Deos [...]”, além de só ter aceitado a condição de rei graças aos fortes argumentos de frei João da Barroca de que "a Deus prazia de ele ser rei" de Portugal (FERNÃO LOPES, 1977, p. 43 e 369). ${ }^{11}$ Do mesmo modo, quando já era rei, só decidiu pela tomada de Ceuta depois de ouvir alguns letrados do reino se aquilo era por "serviço de Deus", única razão que justificava o risco, pois considerava que uma coisa só "é boa e honesta" quando "Deus inteiramente é servido" (ZURARA, 1915, p. 30). Lugares comuns que, se não cabem ser lidos como sinceros ou julgados como tais, revelam, sem dúvida, as convenções críveis naquele tempo e que podiam figurar nos escritos históricos de então - registros, vale lembrar, feitos por homens que gozavam de prestígio e respeito - como pertinentes. O ideal era, pois, que seguissem a Deus, apesar de nem sempre seus sinais serem facilmente interpretáveis. D. Duarte, o sucessor de D. João I no trono, por exemplo, era, como seu pai, um rei "muito desejoso de servir a Deos", mas não soube ler os seus sinais para que não autorizasse a ida dos seus irmãos, D. Henrique e D. Fernando, a Tânger (RUI DE PINA, 1977, p. 519-522). Incompreensão que lhe custou a vida do irmão mais novo, segundo o cronista.

Ao lado da fé, outras virtudes, como a justiça, a temperança e a fortaleza são apontadas como próprias do rei bastardo e de seus descendentes. Homens apontados, por exemplo, como dotados "de todas as outras perfeições do corpo, e da alma" (RUI DE PINA, 1977, p. 495) ou temperados "em todos os impulsos da carne" (RUI DE PINA, 1977, p. 753), além de continentes (RUI DE PINA, 1977, p. 1031). Aproximavam-se, assim, em certos pontos de D. Dinis, mas se distanciavam dele nos seus excessos (RUI DE PINA, 1977, p. 234; 1952, p. 19). Faziam, pois, lembrar mais os virtuosos espalhados ao longo do passado e que atuaram em várias partes. De forma que o passado, a despeito da ruptura, continuava a ser o tempo de maior prestígio - assim 
como a memória era soberana em relação à inteligência e a previdência (COLEMAN, 1992, p. 42-43). Era ainda bem aceita a fórmula de que os bons exemplos deviam ser seguidos e os maus, conhecidos, para que assim pudessem ser evitados. Mesmo em circunstâncias desfavoráveis, portanto, a noção de que a função da história era ser fonte de ensinamento, de que a história era uma espécie de seiva da existência, continuou a ser reafirmada, porém, as quebras nas continuidades dinásticas obrigaram os cronistas a buscarem outro padrão de continuidade, não mais a partir de uma ordem sucessiva, mas de uma ordem estabelecida por articulações morais. O mérito tinha se sobreposto ao sangue. Os modelos do passado a serem espelhados não eram necessariamente os do antecessor, mas os dos reis virtuosos conhecidos e reconhecidos, e cuja arte de governar era ordenada por fins éticos (SENELLART, 2006, p. 203).

THE NECTAR OF THE PAST IN THE PORTUGUeSe AND CASTILlian's HiSTORICAL KNOWLEDGE (14XIV-XV).

ABSTRACT: The proposition of this study is, from the analysis of the fourteenth and fifteenth century chronicles, bring light over the topoi used by the chroniclers/historians of this time to assert and reassert that their writing should have been read as a source of teachings. Giving away, as thus, the topos of History as a master of life and remolding it according to the present's interests, the chroniclers ordered the past from this normative idea. Which role this ideal in the construction of History meets is precisely the objective of this study, however, with emphasis in the dead-lock that the chroniclers who had to value the past faced, but to justify a disruption: In other words, historians that talked about both originative successors new dynasties: Avis, in Portugal, and Trastâmara, in Castile.

Keywords: The Writing of History; Pero Lopez of Ayala; Fernão Lopes.

\section{LA SAVIA DEL PASADO EN EL SABER HISTÓRICO PORTUGUÉS Y CASTELLANO (XIV-XV)}

RESUMEN: Este estudio se basa en el análisis de las crónicas de los siglos XIV y XV, arrojando luz sobre los topoi utilizados por los cronistas / historiadores de esa época para afirmar y reafirmar que sus escritos deben ser leídos como una fuente de conocimiento. Al usar el topos de la historia como maestra de la vida y reorganizándolo de acuerdo a sus intereses presentes, los cronistas han ordenado el pasado a partir de esa idea regulativa. Qué lugar ocupa ese ideal en la construcción de su historia es precisamente el propósito del estudio, sin embargo, haciendo hincapié en el callejón sin salida que enfrentaron los cronistas que tuvieron que valorar 
el pasado, mas también justificar una ruptura, o sea, los historiadores que han tratado las dos crisis sucesivas originarias de nuevas dinastías: Avis, en Portugal, y Trastámara, en Castilla.

PALABRAS CLAVE: Escrita de la historia, Pero Lopez de Ayala, Fernão Lopes.

\section{NOTAS}

${ }^{1}$ No século XIV, Castela e Portugal, viram ascender duas novas dinastias, uma inaugurada por um fratricida, D. Henrique II, e outra por um bastardo, D. João I.

${ }^{2}$ Reinhart Koselleck, tendo como finalidade mostrar como este topos da história Magistra Vitae se dissolve - quando um futuro inaudito e já não inspirado pelo passado é proposto pelos revolucionários franceses -, chega mesmo a propor uma continuidade até o século XVIII da noção ciceroniana

${ }^{3}$ Até opostas, segundo Halbawchs, dado que "a condição necessária para que exista a memória é que o sujeito que lembra, indivíduo ou grupo, tenha a sensação de que ela remonta a lembranças de um movimento contínuo", enquanto, no caso da história "há uma interrupção entre a sociedade que lê essa história e os grupos de testemunhas ou atores, outrora, de acontecimentos que nela são relatados". A primeira seria, pois, "vivida", e a segunda "impessoal."

${ }^{4}$ A oposição entre real e imaginado há muito vem sendo apontada como simplificação a ser evitada pelos historiadores, posto que os ideais de uma sociedade não se constituem menos fundamentais do que as práticas efetivas.

${ }^{5}$ François Hartog, no seu empenho de encontrar modalidades de tempo ou «regime de historicidade» ao longo da história, propõe que o tempo cristão ganhe sentido em referência a tudo aquilo que já se cumpriu (os episódios do Antigo e Novo Testamento) e em referência a uma esperança do fim, uma espera do Julgamento.

${ }^{6}$ Compilação de crônicas escritas por diversos cronistas: Fernán Pérez de Guzmán, Diego de Valera, Diego Enríquez del Castillo, Fernando del Pulgar, Lorenzo Galíndez de Carvajal, Andrés Bernáldez, Pero López de Ayala.

${ }^{7}$ Carta que Gomes Eanes da Zurara, comendador da Ordem de Cristo, escreveu ao senhor rei quando lhe enviou este livro.

${ }^{8} \mathrm{Na}$ tradição judaico-cristã, o homem se entendia constituído pela história, mas uma história exterior a seu ser, comandada pela Providência.

9 Afinal, o real não deve ser visto em oposição ao ideal, mas como um espaço onde se cruzam imaginações.

${ }^{10}$ Para lembrar a célebre interpretação de Kantorowicz sobre as duas dimensões da realeza.

\section{FONTES}

AYALA, D. P. L. de. Cronicas de los reyes de Castilia. Don Pedro, Don Enrique II, Don Juan I, Don Enrique III, por D. Pedro Lopez de Ayala. Tomo I-II. Madrid: Imprenta de A. de Sancha, 1779-80.

BARROS, João de. Asia. Dos feitos que os portugueses fizeram no descobrimento e conquista dos mares e terras do Oriente. Reedição fac-similada das $1^{\text {a }}, 2^{\mathrm{a}}$ e $3^{\mathrm{a}}$ Décadas, vol. III. Lisboa: Imprensa Nacional / Casa da Moeda, 1988.

CASAS, Bartolomé de las. Historia de las Indias. Tomo I. Madrid : Impr. de Miguel Ginesta, 1875.

CASTANHEDA, Fernão Lopes de. História do descobrimento e conquista da Índia pelos portugueses, introdução e revisão de M. Lopes de Almeida, 2 vol., Porto: Lello \& Irmão, 1979 (Tesouros da literatura e história), 1924.

Crónica dos Sete Primeiros Reis de Portugal. Ed. Crítica de Carlos da Silva Tarouca, Lisboa: Academia Portuguesa da História, 1952. 3 v.

DIEGO DE VALERA. Memorial de Diversas Hazañas. In : Crónicas de los reyes de Castilla desde Don Alfonso el Sabio, hasta los católicos Don Fernando y Doña Isabel. Biblioteca de autores españoles, desde la formacion del lenguaje hasta nuestros dias. 
Coleccion ordenada por Don Cayetano Rosell. Tomo III. Madrid: M. Rivadeneyra, 1878.

GALINDEZ DE CARVAJAL, L. Memorial y registro breve de los lugares donde el Rey y Reina Católicos, nuestros Señores, estuvieron cada año ... In: Crónicas de los reyes de Castilla desde Don Alfonso el Sabio, hasta los católicos Don Fernando y Doña Isabel. Biblioteca de autores españoles, desde la formacion del lenguaje hasta nuestros dias. Coleccion ordenada por Don Cayetano Rosell. Tomo III. Madrid: M. Rivadeneyra, 1878.

GARCÍA DE CASTROJERIZ, J. Glosa Castellana al Regimiento de Principes de Egidio Romano. Edicion y estudio preliminar y notas de Juan Beneyto Perez. Madrid: Centro de Estudios políticos y constitucionales, 2005.

HERNANDO DEL PULGAR. Crónica de los Señores Reyes Católicos Don Fernando y Doña Isabel de Castilla y de Aragón. Cotexada con antiguos manuscritos y aumentada de varias ilustraciones y enmiendas. Valencia: En la imprenta de Benito Monfort, 1780. Livro dos Conselhos de El-rei D. Duarte (Livro da Cartuxa). Ed. Diplomática de João José Alves Dias. Lisboa: Estampa, 1980.

LOPES, F. Crónica de D. João I de boa memória. Parte Primeira, ed. Braamcamp Freire. Lisboa: Imprensa Nacional /Casa da Moeda, 1977.

Crónica de D. João I de boa memória. Parte Segunda, ed. William J. Entwisle.

Lisboa: Imprensa Nacional /Casa da Moeda, 1977.

RUI DE PINA. Crónicas. Introdução e revisão de M. Lopes de Almeida. Porto: Lello \& Irmão, 1977.

TOMÁS DE AQUINO. Suma teológica. Caxias do Sul: SULINA UCS, 1980, vol. 09. WENDOVER, R. Flowers of history. Translated by J.A. Giles. London: Henry G. Born, 1849.

ZURARA, G. E. Crónica da Tomada de Ceuta. Edição Francisco Maria Esteves Pereira. Lisboa: Academia das Sciências de Lisboa, 1915.

Crónica de Guiné. Introdução, novas anotações e glossário de José de Bragança. Porto: Livraria Civilização, 1973.

\section{REFERENCIAS}

BECEIRO PITA, I. Libros, lectores y bibliotecas en la España Medieval. Múrcia: Nausícaä, 2007.

BUESCU, Ana Isabel. Imagens do Príncipe - Discurso normativo e representação (1525-49). Lisboa: Cosmos, 1996.

CARRUTHERS, Mary. Le Livre de la Mémoire. La mémoire dans la culture médiévale. Macula, 2002.

COLEMAN, Janet. Ancient and medieval memories. Studies in the reconstruction of the past. New York: Cambridge University Press, 1992.

DELUZ, Christiane. Découvrir um monde imaginé, Le livre de Jean de Mandeville. In: LECOQ, D.; CHAMBARD, A. Terre à découvrir, terres à parcourir. Exploration et connaissance du monde XII ${ }^{\mathrm{e}}-\mathrm{XIX}^{\mathrm{e}}$ siècles. Paris: L'Harmattan, 1998.

DOMINGUES, I. O grau zero do conhecimento. O problema da fundamentação das ciências humanas. São Paulo: Loyola, 1991.

FERRO, J. N. La elaboración de la doctrina política en el discurso cronístico del Canciller Ayala. In: Incipit. No 11, Buenos Aires, 1991.

FUNES. L. Del Alfonso X el Sabio ao Canciller Ayala: variaciones del relato histórico. Conclusiones del seminario dictado en la Universidad de Buenos Aires. Buenos Aires: 
CONICET- SECRIT, s/p, 2002. (Disponível em: http://parnaseo.uv.es /Memorabilia/ Memorabilia7/Funes/Funes.htm; Acesso em 14 de março de 2013).

GILSON, E. A Filosofia na Idade Média. São Paulo: Martins Fontes, 1995.

GÓMEZ REDONDO, F. De la crónica general a la real. Transformaciones ideológicas en Crónica de tres reyes. In: MARTIN, G. La Historia alfonsí: el modelo y sus destinos (siglos XIII- XV). Madri: Casa de Velázquez, 2000.

GUENÉE, Bernard. Histoire et culture historique dans l'Occident médiéval. Paris: Aubier Montaigne, 1980.

GUINSBURG, J. Romantismo, Historicismo e História. In: Romantismo. São Paulo: Perspectiva, 1993.

GUITTON, J. Le present, le passé et l'avenir. In: Le temps et l'éternité chez Plotin et saint Augustin. Paris: J. Vrin, 1959.

HALBWACHS, Maurice. A memória coletiva. São Paulo: Centauro, 2006.

HARTOG, F. Régimes d'Historicité. Présentisme et Expériences du Temps. Paris: Seuil, 2003.

KANTOROWICZ, E. H. Os dois corpos do rei. Trad. Cid Knipel Moreira. São Paulo: Companhia da Letras, 1998.

KOSELLECK, R. Historia Magistra Vitae: sobre a dissolução do topos na história moderna em movimento. In: KOSELLECK, R. Futuro passado: contribuição à semântica dos tempos históricos. Trad. Wilma Patrícia Maas e Carlos Almeida Pereira. Rio de Janeiro: Contraponto, 2006.

LACROIX, J. Kant e o Kantismo. Trad. Maria Manuela Cardoso. Porto: Rés-Editora, 2001.

LE GOFF, J. Progresso/Reação. In: Enciclopédia Einaudi. Trad. Irene Ferreira. Lisboa: Imprensa Nacional/ Casa da Moeda, 1984.

MURPHY, J. La Retórica en la Edad Media. Historia de la teoria de la retórica desde San Agustin hasta el Renascimento. Cidade do México: Fundo de Cultura Económica, 1986.

NOGALES RINCÓN, D. Los espejos de príncipes en Castilla (siglos XIII-XV): un modelo literário de la realeza bajomedieval. In: Medievalismo. Revista de la Sociedad Española de Estudios Medievales. № 16, Múrcia: Universidad de Murcia, 2006.

RICOUER, P. La mémoire, l'histoire, l'oubli. Paris: Seuil, 2000.

SENELLART, M. As artes de governar. Do regimen medieval ao conceito de governo. Trad. Paulo Neves. São Paulo: Editora 34, 2006.

ULLMANN, W. Historia del pensamiento político en la Edad Media. Barcelona: Ariel, 1992.

VENTURA, Margarida Garcez. Igreja e Poder no séc. XV - Dinastia de Avis e Liberdades Eclesiásticas (1383-1450). Lisboa: Colibri, 1997.

VENTURA, Margarida Garcez. O messias de Lisboa. Um estudo de mitologia política (1383-1415). Lisboa: Cosmos, 1992.

VEYNE, P. Acreditavam os gregos em seus mitos? Trad. Horácio González e Milton Meira Nascimento. São Paulo: Brasiliense, 1984.

YATES, Frances Amelia. A arte da memória. Trad. Flavia Bancher. Campinas, SP: Editora da Unicamp, 2007. 